\title{
Factors related to orientation of search for dental care in high risk pregnancy
}

\section{Jessica Galvan 1}

iD https://orcid.org/0000-0002-3261-8521

Danielle Bordin 2

iD https://orcid.org/0000-0001-7861-0384

Cristina Berger Fadel 3

iD https://orcid.org/0000-0002-7303-5429

Fabiana Bucholdz Teixeira Alves 4

iD https://orcid.org/0000-0001-9955-1811

\footnotetext{
1 Programa de Residência Multiprofissional em Neonatologia. Universidade Estadual de Ponta Grossa. Av. General Carlos Cavalcanti, 4748, Bloco M. Campus Uvaranas. Ponta Grossa, PR, Brasil. CEP: 84.030-900. E-mail: jegalvan21@gmail.com

2 Departamento de Enfermagem e Saúde Pública. Universidade Estadual de Ponta Grossa. Ponta Grossa, PR, Brasil.

3,4 Departamento de Odontologia. Universidade Estadual de Ponta Grossa. Campus Uvaranas. Ponta Grossa, PR, Brasil
}

\begin{abstract}
Objectives: to relate the search for dental care during pregnancy to sociodemographic, gestational and dental characteristics.

Methods: quantitative approach study with cross-sectional design carried out with highrisk pregnant women, from January to May 2018. Statistical analysis was performed using Pearson's chi-square association test and Fisher's exact test, followed by logistic regression analysis and odds ratio calculation.

Results: the final sample was composed of 190 pregnant women and the guidance for seeking dental care was significantly related to issues related to Prenatal Dental Care, regarding safety $(p=0.025)$, effective search $(p<0.0001)$ and the Unit Basic Health Care as a place of assistance $(p=0.0018)$. Pregnant women who did not receive search guidance are 19.6 more likely to not seek this service $(p<0.001)$, when they seek it without guidance, they have 6.3 more chances to seek private services $(p=0.014)$ and when they do not receive guidance, they are 4.5 more likely to not feel secure in relation to this assistance $(p=0.005)$.

Conclusion: the guidance and encouragement provided by the health team is paramount in pregnant woman's decision to seek assistance, especially in the context of Primary Health Care, and is characterized as a strategic tool in reducing insecurities related to dental treatment during pregnancy.

Key words Prenatal care, Oral health, Pregnant women, Pregnancy, High risk
\end{abstract}

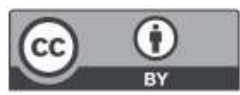




\section{Introduction}

Regular dental care is an essential component for maintaining oral health, being essential for the general population to guarantee their quality of life. Considering specifically the public of pregnant women, preventive care with strict control of the etiological agents of prevalent oral diseases becomes essential, as evidence shows an association between oral health care during pregnancy and improvements in systemic aspects. 1,2

Although not yet consolidated in the national and international literature, the term Prenatal Dental Care (PDC) has been used by researchers to report ongoing oral health care for pregnant women and their future babies, with an emphasis on preventive, educational and curative aspects.3,4 This is an essential condition to maintain or restore oral health, as it allows pregnant women to have better oral conditions and to minimize possible undesirable changes in the birth and development of her baby. ${ }^{2}$ Inserted in this process of maternal-infant dental care, are high-risk pregnant women, represented by those whose pregnancy involves greater chances of complications in the life of the mother or fetus when compared to the average of pregnancies. 5 Given the increased risk represented by this special group of pregnant women, greater attention is required to this portion of the population and to the formulation of specific integrated care strategies, by different professionals of health, including the dental surgeon.

In the context of public health policies, the organization of maternal and child health in the Unified Health System (SUS- Portuguese acronym), represented by Rede Cegonha, aims to provide all pregnant women with health, quality of life and wellbeing during pregnancy, childbirth, post-delivery and child development up to the first two years of life. 6 In this way, comprehensive care to maternal and child health and the increase in obstetric and neonatal care are made possible by SUS and guaranteed by its principles of universality and integrality, which advocate the right to carry out the PDC, regardless of the gestational risk. ${ }^{7}$

Given the above and the importance that new studies on the PDC currently assume, the objective of this study is to relate the orientation for seeking dental care during pregnancy with sociodemographic characteristics and health conditions of high-risk pregnant women who underwent prenatal care in a university hospital.

\section{Methods}

This is a quantitative approach study, with a crosssectional design, carried out with high-risk pregnant women referred to the Regional University Hospital of Campos Gerais (HURCG) for medical prenatal care, located in the city of Ponta Grossa - Paraná, Brazil. The HURCG is a health reference institution for the eastern macro-region of the state of Paraná, comprising twelve small and medium-sized municipalities.

The inclusion criteria for the study were highrisk pregnant women who were in the 3rd gestational trimester, over 18 years old, who underwent prenatal care at that hospital and who agreed to participate in the research. The risk stratification recommended by the Health Department of the State of Paraná was followed 5 (Table 1). Pregnant women with any acute or chronic condition that limited their ability to participate in the study were excluded. Data collection took place between January and May 2018. The sample cut limited to 3rd trimester pregnant women was justified by the need to homogenize the sample regarding the approach period, in order to eliminate the possible bias that, when approached in early trimesters, they might not have had dental appointments yet.

Sampling was carried out in a simple random way, alternating the days of information collection, aiming to cover pregnant women from all municipalities affiliated to that hospital. This strategy was organized in order to ensure relative homogeneity in the number of pregnant women in each location, since prenatal care is organized on different days of the week, considering that each day, one or two municipalities are covered according to the population size.

For the sample calculation, the average number of monthly consultations provided to high-risk pregnant women in the third trimester of pregnancy was considered $(n=100)$, multiplied by the estimated months for collection $(n=5)$, with a precision of $5 \%$, confidence level of $95 \%$ and design effect 1 , for a $27 \%$ prevalence of pregnant women who received dental care during pregnancy, resulting in a sample of 190 pregnant women. The imputed prevalence was based on a previous study, with a population with similar characteristics. 8 For the sample estimate calculation, the Epi. Info 7.1.4 software was chosen (Figure 1)

To obtain the data, a new structured form was used, with sociodemographic and health condition subjects and guidance on access and quality of the PDC questions, specifically formulated for the 
Table 1

Stratification criteria for high gestational risk. 5

Preexisting conditions

Hypertension under treatment

Addiction to illicit drugs

Cardiac diseases under treatment and/or under followup

Pneumoties under treatment

Nephropathies under treatment and/or in follow-up

Diabetes

Hemopathies (except mild and moderate anemia, physiological of pregnancy)

Uterus/vaginal malformation

Infectious diseases (consider the local epidemiological situation, periodontal diseases and their impact on pregnancy)

Epilepsy

\section{Clinical complications}

Hypertensive syndrome in current pregnancy

Twin pregnancy

$\mathrm{Rh}$ isoimmunization

Gestational diabetes mellitus

Intrauterine growth retardation (estimated fetal weight below the $10^{\text {th }}$ percentile)

Infectious-contagious diseases experienced during the current pregnancy (recurrent urinary tract infection, respiratory tract diseases, rubella, HIV, toxoplasmosis, syphilis, Zika virus infection, influenza influenza, viral hepatitis, other arboviruses with fetal repercussions)
Autoimmune diseases

Previous uterus/vaginal surgery (outside of pregnancy)

Hypothyroidism (changed T4L or patient undergoing treatment)

Neoplasms

Morbid obesity

Psychosis and severe depression

Bariatric Surgery (less than 2 years after surgery)

Hyperthyroidism

Addiction to legal drugs (smoking/alcoholism) with clinical complications or other maternal/fetal risk factor.

Previous placent

Uterine bleeding

Fetal malformation

Abrupt change in BMI curve

Premature labor

Premature amniorrhexis (below 37 weeks of gestation)

Source: Paraná, 2018.6

research and based on validated instruments from Brazil's Ministry of Health and from previous studies. The dependent variable was 'Orientation to seek dental care during pregnancy' (considering the current pregnancy and the answer dichotomized into "yes" or "no" depending on whether or not there was guidance provided by any member of the primary or hospital health team), and as independent variables: sociodemographic data, gestational data, general and oral health data and data related to the PDC. It is worth noting that the independent variable "effective search for dental care during pregnancy" was repre- sented by the minimum frequency of a dental appointment in each gestational trimester.

Data collection was performed through individual interviews, conducted by two researchers trained to gather the necessary information and help with any doubts, without influencing the answers. The interview lasted an average of ten minutes and the participants were recruited while waiting for the prenatal consultation at the hospital, and later directed to a reserved environment inside the clinic.

To ensure the understanding of the instrument regarding the text, the vocabulary used and the sensi- 
Figure 1

Sampling process flowchart.

Monthly average of consultations for pre nant women in the 3 rd gestational trimester $(n=100)$

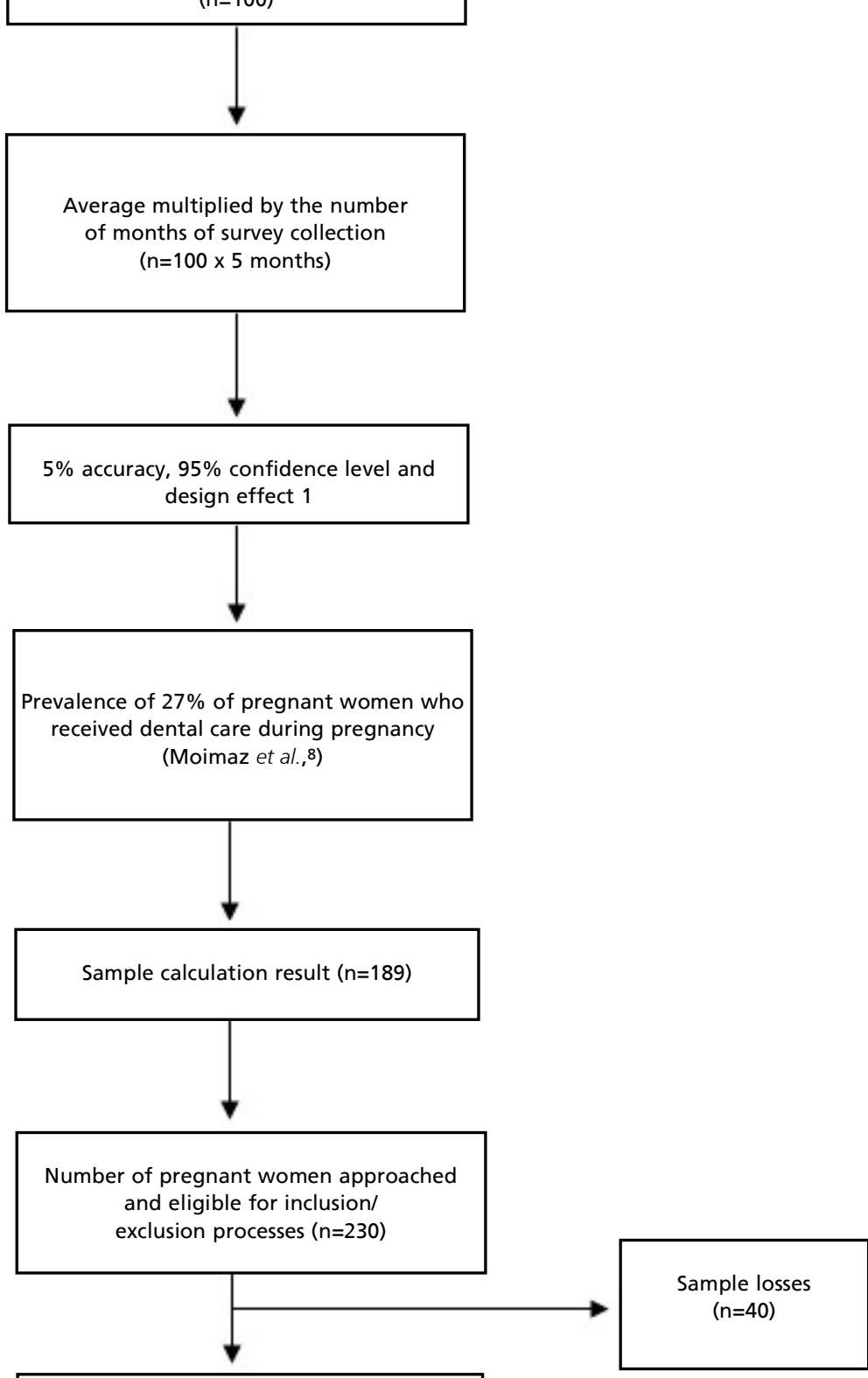

Final study sample $(n=190)$ 
tivity of the responses, a pilot study was carried out with 40 pregnant women attending the study hospital. The data obtained at this stage were not part of the sample, as the pilot study indicated the need to adapt the data collection instrument.

As for data analysis, in the first stage, descriptive statistics of all variables were obtained, through absolute and relative frequency. In the second stage, bivariate analysis was conducted, seeking to identify the independent associations between the investigated variables, using Pearson's chi-square and Fisher's exact tests.

Next, logistic regression analysis was performed using the Stepwise input method, based on the likelihood value and to estimate the magnitude of the effect of each variable by calculating the odds ratio (OR) and their respective Confidence Intervals (CI) to $95 \%$. The variables that presented a value of $p \leq 0.20$ in the bivariate analysis were selected to enter the multiple model, with those that reached $p \leq 0.05$ remaining in the model. The SPSS ${ }^{\circledR}$ (Statistical Package for the Social Sciences) program was used for data analysis. The model had an explanatory capacity of $95.6 \%$.

The research was approved by the Ethics Committee for Research with Human Beings of the State University of Ponta Grossa (Opinion $N^{\circ}$. 2,364,648; CAAE: 78544717.4.0000.0105, respecting the dictates of Resolution $466 / 12$ of the National Health Council and international standards for research with humans). The participating pregnant women consented to participate in the research by signing the Informed Consent Term and the Site Authorization Term for the research was signed by the academic board of the university hospital, authorizing the research to be carried out in the high-risk pregnant women outpatient clinic.

\section{Results}

Considering sample losses (refusal to participate $\mathrm{n}=23$; partial results $\mathrm{n}=10$ and duplicate responses $\mathrm{n}=7$ ), the final sample consisted of 190 pregnant women at high gestational risk (Figure 1). The average age was 32 years $(18 \pm 47)$, with a higher prevalence of women who are married or in a stable union ( $\mathrm{n}=106 / 55.8 \%)$, completed basic or elementary education $(\mathrm{n}=118 / 62.1 \%)$, family income between one and two minimum wages $(\mathrm{n}=88 / 46.3 \%)$ and household occupation ( $\mathrm{n}=117 / 61.6 \%)$.

Sociodemographic variables did not show any association with 'Seek Guidance for Dental Care during Pregnancy' (Table 2) $(p>0.05)$. Table 2 shows that the frequency of pregnant women oriented to seek dental care during pregnancy was higher in women with complete basic or elementary education $(\mathrm{n}=119 / 62 \%)$, family income range between one and two minimum wages $(n=109 / 57.4 \%)$, married or in a stable union $(\mathrm{n}=108 / 56.8 \%)$ and housework $(\mathrm{n}=118 / 62.1 \%)$.

Table 3 shows that gestational, general health and oral health data did not show a relationship of dependence with the variable 'Orientation to Search for Dental Care during Pregnancy' $(p>0.05)$. However, it can be identified that most pregnant women oriented to seek dental care during pregnancy were women with some preexisting clinical condition or clinical complications (Table 1), multipregnant women, without history of miscarriage or premature birth, no history of children with low weight at birth, with the habit of having dental appointments in the pre-pregnancy period, no change in oral health habits during pregnancy, no perception of changes in the oral cavity during pregnancy, no report of dental pain in the last six months prior to the interview and with a positive evaluation of their oral health.

Specifically regarding the PDC, pregnant women who received guidance to seek dental care during pregnancy were significantly more likely to consider the dental care safe during this period $(p=0.025)$ and to effectively seek the dental surgeon during the gestational period $(p<0.001)$, with the Basic Health Unit (BHU) being the main place of choice for seeking dental care $(p=0.002)$ (Table 4$)$.

The multivariate analysis showed that pregnant women who did not receive guidance to seek dental care during pregnancy have 19.6 more chance of not seeking dental care $(p<0.001)$, and that when they seek the service without guidance, there are 6.3 more chances of being by private services $(p=0.014)$. Still, when they do not receive guidance to seek dental care during pregnancy, they have 4.54 more chances of not feeling secure in this type of care $(p=0.005)$ (Table 4).

\section{Discussion}

The encouragement to seek dental care, the referral of pregnant women to the service and oral health education during prenatal care are identified as key factors for the decision of pregnant women to seek dental care during pregnancy. Such findings corroborate the present study, and demonstrate that the chances of pregnant women seeking dental care during pregnancy are lower when they do not receive this specific guidance from a health professional.

In this sense, within the scope of Brazilian public 
Table 2

Sociodemographic variables of pregnant women at high gestational risk linked to the Regional University Hospital of Campos Gerais, according to the dependent variable 'Search Guidance for Dental Care in Pregnancy'. Ponta Grossa, Paraná, $2018(n=190)$.

\begin{tabular}{|c|c|c|c|c|c|c|c|}
\hline \multirow[t]{3}{*}{ Variables } & \multicolumn{7}{|c|}{$\begin{array}{l}\text { Received orientation to seek a dental surgeon during the } \\
\text { current pregnancy }\end{array}$} \\
\hline & \multicolumn{2}{|c|}{ Yes $(n=169)$} & \multicolumn{2}{|c|}{ No $(n=21)$} & \multicolumn{2}{|c|}{ Total } & \multirow[t]{2}{*}{$p$} \\
\hline & $\mathrm{n}$ & $\%$ & $\mathrm{n}$ & $\%$ & $\mathrm{n}$ & $\%$ & \\
\hline Age (years) & & & & & & & 0.11 \\
\hline $18-25$ & 71 & 42.0 & 12 & 57.1 & 83 & 43.7 & \\
\hline $26-35$ & 72 & 42.6 & 4 & 19.1 & 76 & 40.0 & \\
\hline$>35$ & 26 & 15.4 & 5 & 23.8 & 31 & 16.3 & \\
\hline Scholarity & & & & & & & 0.61 \\
\hline Elementary or middle school complete & 106 & 62.7 & 12 & 57.1 & 118 & 62.1 & \\
\hline High school or superior complete & 63 & 37.3 & 9 & 42.9 & 72 & 37.9 & \\
\hline Family income (minimum wage) & & & & & & & 0.66 \\
\hline Until 1 & 72 & 42.6 & 10 & 47.6 & 82 & 43.1 & \\
\hline $1-2$ & 97 & 57.4 & 11 & 53.4 & 108 & 56.9 & \\
\hline Marital status & & & & & & & 0.42 \\
\hline Single/other & 73 & 43.2 & 11 & 52.4 & 84 & 44.2 & \\
\hline Married/stable union & 96 & 56.8 & 10 & 47.6 & 106 & 55.8 & \\
\hline Occupation & & & & & & & 0.26 \\
\hline General Services & 31 & 18.3 & 7 & 33.3 & 38 & 20.0 & \\
\hline Housewife & 105 & 62.1 & 11 & 52.4 & 116 & 61.0 & \\
\hline Other & 33 & 19.6 & 3 & 14.3 & 36 & 19.0 & \\
\hline
\end{tabular}

\section{Table 3}

Health conditions of pregnant women at high gestational risk linked to the Regional University Hospital of Campos Gerais, according to the dependent variable 'Search Guidance for Dental Care in Pregnancy'. Ponta Grossa, Paraná, $2018(n=190)$.

\begin{tabular}{|c|c|c|c|c|c|c|c|}
\hline \multirow[t]{3}{*}{ Variables } & \multicolumn{7}{|c|}{$\begin{array}{l}\text { Received orientation to seek a dental surgeon during the } \\
\text { current pregnancy }\end{array}$} \\
\hline & \multicolumn{2}{|c|}{ Yes $(n=169)$} & \multicolumn{2}{|c|}{ No $(n=21)$} & \multicolumn{2}{|c|}{ Total } & \multirow[t]{2}{*}{$p$} \\
\hline & $\mathrm{n}$ & $\%$ & $\mathrm{n}$ & $\%$ & $\mathrm{n}$ & $\%$ & \\
\hline \multicolumn{8}{|l|}{ Systemic and gestational health } \\
\hline Preexisting clinical condition or clinical complications & & & & & & & 0.34 \\
\hline Present & 100 & 59.2 & 15 & 71.4 & 115 & 60.5 & \\
\hline Absent & 69 & 40.8 & 6 & 28.6 & 75 & 39.5 & \\
\hline First pregnancy & & & & & & & 0.87 \\
\hline Yes & 51 & 30.2 & 6 & 28.6 & 57 & 30.0 & \\
\hline No & 118 & 69.8 & 15 & 71.4 & 133 & 70.0 & \\
\hline Miscarriage history * & & & & & & & 0.53 \\
\hline Yes & 29 & 24.6 & 5 & 33.3 & 34 & 25.6 & \\
\hline No & 89 & 75.4 & 10 & 66.7 & 99 & 74.4 & \\
\hline Premature birth history * & & & & & & & 0.07 \\
\hline Yes & 17 & 14.4 & 5 & 33.3 & 22 & 16.6 & \\
\hline No & 101 & 85.6 & 10 & 66.7 & 111 & 83.4 & \\
\hline Low birth weight child history * & & & & & & & 0.24 \\
\hline Yes & 16 & 13.6 & 4 & 26.7 & 20 & 15.0 & \\
\hline No & 102 & 86.4 & 11 & 73.3 & 113 & 85.0 & \\
\hline
\end{tabular}


Health conditions of pregnant women at high gestational risk linked to the Regional University Hospital of Campos Gerais, according to the dependent variable 'Search Guidance for Dental Care in Pregnancy'. Ponta Grossa, Paraná, $2018(n=190)$.

\begin{tabular}{|c|c|c|c|c|c|c|c|}
\hline \multirow[t]{3}{*}{ Variables } & \multicolumn{7}{|c|}{$\begin{array}{l}\text { Received orientation to seek a dental surgeon during the } \\
\text { current pregnancy }\end{array}$} \\
\hline & \multicolumn{2}{|c|}{ Yes $(n=169)$} & \multicolumn{2}{|c|}{ No $(n=21)$} & \multicolumn{2}{|c|}{ Total } & \multirow[t]{2}{*}{$p$} \\
\hline & $\mathrm{n}$ & $\%$ & $\mathrm{n}$ & $\%$ & $n$ & $\%$ & \\
\hline \multicolumn{8}{|l|}{ Oral Health } \\
\hline \multicolumn{8}{|l|}{ Habit of dental appointments in the } \\
\hline pre-pregnancy period & & & & & & & 0.15 \\
\hline Yes & 122 & 72.2 & 12 & 57.1 & 134 & 70.5 & \\
\hline No & 47 & 27.8 & 9 & 42.9 & 56 & 29.5 & \\
\hline Change in oral hygiene habits & & & & & & & 0.56 \\
\hline Yes & 33 & 19.5 & 3 & 14.3 & 36 & 19.0 & \\
\hline No & 136 & 80.5 & 18 & 85.7 & 154 & 81.0 & \\
\hline Self-perception of change in the oral cavity & & & & & & & 0.77 \\
\hline Yes & 67 & 39.6 & 9 & 42.9 & 76 & 40.0 & \\
\hline No & 102 & 60.4 & 12 & 57.1 & 114 & 60.0 & \\
\hline Toothache in the last 6 months & & & & & & & 0.58 \\
\hline Yes & 50 & 29.6 & 5 & 21.8 & 55 & 29.0 & \\
\hline No & 119 & 70.4 & 16 & 76.2 & 135 & 71.0 & \\
\hline Oral Health Evaluation & & & & & & & 0.13 \\
\hline Positive & 116 & 68.6 & 11 & 52.4 & 132 & 69.5 & \\
\hline Negative & 53 & 31.4 & 10 & 47.6 & 63 & 30.5 & \\
\hline \multicolumn{8}{|l|}{ Prenatal Dental Care } \\
\hline Knowledge about the term PDC & & & & & & & 0.20 \\
\hline Yes & 61 & 36.1 & 5 & 23.8 & 66 & 34.7 & \\
\hline No & 108 & 63.9 & 16 & 76.2 & 124 & 65.3 & \\
\hline Security regarding dental care & & & & & & & 0.025 \\
\hline Yes & 155 & 91.7 & 16 & 76.2 & 171 & 90.0 & \\
\hline No & 14 & 8.3 & 5 & 23.8 & 19 & 10.0 & \\
\hline Effective search for dental care & & & & & & & $<0.001$ \\
\hline Yes & 160 & 94.7 & 10 & 46.6 & 170 & 89.5 & \\
\hline No & 9 & 5.3 & 11 & 52.4 & 20 & 10.5 & \\
\hline $\mathrm{BHU}$ as a search location for dental care ** & & & & & & & 0.002 \\
\hline Yes & 146 & 91.2 & 6 & 60.0 & 152 & 80.0 & \\
\hline No & 14 & 8.8 & 4 & 40.0 & 54 & 20.0 & \\
\hline
\end{tabular}


Table 4

Multiple analysis of the association between guidance for seeking dental care during pregnancy and the independent variables. Ponta Grossa, Paraná, $2018(n=190)$.

\begin{tabular}{lcc}
\hline Variable & OR (Cl95\%) & $p$ \\
\hline Effective search for dental care & & $<0.001$ \\
Yes & 1,00 & \\
No & $19.6(6.6-58.1)$ & \\
BHU as search location for dental care & 1.00 & 0.014 \\
$\quad$ Yes & $6.3(1.5-27.5)$ & \\
No & & \\
Security regarding dental care & 1.00 & 0.005 \\
Yes & $4.54(3.06-6.72)$ & \\
No & & \\
\end{tabular}

Explicative capacity of the model $95.6 \%$.

policies, the guidelines of the Integral Assistance Policy for Women's Health (IAPWH) provide that when starting prenatal care, the pregnant women must be referred to a dental appointment, which must include guidance, prevention and diagnosis actions, and treatment plan. 13 Also, the early identification of pregnant women and their risk stratification have been considered in other public agendas, through the implementation of the maternal and child health care network ${ }^{14}$ with a view to even greater safety for certain risk situations for the pregnant woman or for the newborn, with the proposition of differentiated assistance flows.

Considering that the subjects of the current study are pregnant women stratified as high-risk, the contact with the dental surgeon during pregnancy becomes even more relevant, as preexisting oral conditions can be exacerbated during the gestational period and when related to systemic diseases, may favor the occurrence of adverse obstetric events. ${ }^{3}$ The strongest associations established in the literature $^{14}$ are between the presence of periodontal disease and premature delivery, 15,16 low birth weight 17,18 and pre-eclampsia. 19,20

Despite the possibility of periodontal disease as a risk factor for the occurrence of negative obstetric outcomes, it is necessary to carefully interpret these findings in terms of causality, as there is no conclusive evidence on the relation between them. ${ }^{14}$ Even though the effectiveness exerted by periodontal treatment in the reduction of pregnancy complications is notorious, the ideal is for the woman to be approached in the preconception period, since in most cases the intervention during the gestational period seems to occur late in the face of the installed picture of periodontal disease at an advanced stage, which is why reproductive planning can act as an ally in the prevention of oral problems during pregnancy. 21

In Brazil, the inclusion of issues related to oral health in prenatal care is traditionally considered one of the competencies of the physician and the nursing team, although many do not routinely do it or do it wrongly, suggesting the postponement of dental care for the post-pregnancy period, which can reinforce the feeling of fear and insecurity regarding dental care during pregnancy. 22 For this reason, the incorporation of the dental surgeon in the prenatal care team becomes essential, as studies show that the insertion of this professional in the interdisciplinary context of prenatal care is a possible way to make the team and the pregnant women aware of the reduction of risks of oral diseases and systemic problems through the adoption of attitudes favorable to oral health. ${ }^{8}$

Maternal guidance during prenatal care is extremely important, it seeks to establish a bond with the baby's mother and family and initiate preventive guidance, emphasizing the importance of breastfeeding and the first care for the newborn. Dental guidance during the gestational period also impacts the oral health procedures that mothers will carry out in the future with their children, such as the practice of breastfeeding, knowledge about the development of oral diseases and the first visit to the dental surgeon. 23

It is noteworthy here that the search for dental care revealed by the surveyed women was higher than the one of pregnant women in another study, 24 and it demonstrates that, despite the obstacles and barriers to accessing the PDC, the general panorama seems to be more favorable. The average number of dental appointments carried out by the pregnant women was four appointments during the current 
pregnancy, which shows the continuity of dental care and the bond between the pregnant woman and the oral health team, revealing signs of fixation of the PDC. Nevertheless, this data should be carefully observed, since the frequency, in this study, of pregnant women going to the dental surgeon may be related to oral health problems and does not guarantee that important aspects of oral health education have been covered. Still, it should be considered that most pregnant women investigated had pre-existing clinical conditions or complications and had the habit of attending the dental surgeon before pregnancy.

The term Prenatal dental care is new and still not widespread, both within the health team, including dental surgeon, and among pregnant women, 3 the lack of information on the topic being evident. 4 Among the pregnant women surveyed, $65.3 \%$ reported never having heard about the PDC, even though some of them sought care from the dental surgeon during pregnancy. The scarcity of information on the subject ends up neutralizing it among health professionals, reducing the practice of PDC to simple routine care and little relevant from a preventive point of view, when not only the resolution of an installed pain process. $25 \mathrm{Also}$, as most of the pregnant women in this study reported lack of knowledge about the terminology, it becomes essential to encourage and empower oral health agents to develop actions during that period and to incorporate their knowledge and practices throughout the interprofessional work, aiming the improvement of the quality of life of the mother and child.

Concerning the location of search for dental care, the study showed that the vast majority of pregnant women oriented sought dental service in BHU. Despite of the high search for dental care services at the universal health system could be related to the low-income profile of the participants, this result also demonstrates that the access of pregnant women to dental care is being guaranteed and confirms the success of the public policies presented. On the other hand, it was found that non-oriented pregnant women, when they seek dental care, usually do so through a private service. Yet, the search for dental care among SUS users is more usual and systematic during prenatal care when compared to pregnant women assisted in a private or insured service, due to the programmatic offer carried out during this period by the basic health unit. 26

The weight exerted by the orientation to search in the pregnant woman's decision to undergo dental follow-up is not only limited to the search for the service, but also impacts the safety felt by the patient in undergoing the treatment, since non-oriented pregnant women are more likely to feel unsure about the dental appointment. Furthermore, as an aggravating factor, Kateeb and Momany 27 identified that mothers who did not consider dental care safe during pregnancy were significantly more likely to experience oral disease and the accumulation of bacterial plaque. ${ }^{28}$ In this sense, the breaking of paradigms, myths and collective thoughts that involve dental care to pregnant women becomes essential to guarantee the quality of life for the mother and child.

The limitations of this study are related to its regional panorama and a local reality regarding the practice of PDC, which does not allow extrapolation of the findings. The pregnant woman's memory bias can be an aggravating factor considering the time elapsed between her orientation to seek dental care and her participation in the research. Although this is a cross-sectional study, it is noteworthy that the objective was not to identify a causal link between the established variables and the PDC, but an association between them, being required further studies that aim to eliminate possible reverse causal biases between different associations. The scarcity of studies with a sample of high-risk pregnant women hindered the discussion of data in the light of the literature, as most of them were made with pregnant women at usual risk.

It is evident, therefore, that the guidance and encouragement provided by the health team are fundamental in the decision of the pregnant women to seek dental care, with greater potential to perform it in the public service, and it is characterized as a strategic tool in reduction of insecurities related to dental treatment during pregnancy. In this sense, it is possible to suggest that further investigation and evaluation studies of factors related to dental care during high-risk pregnancy should be carried out, especially in the context of public health services.

\section{Acknowledgements}

The authors thank the Post Graduate Program in Health Sciences at the State University of Ponta Grossa.

\section{Author's contribution}

Galvan J: literature review; conceptualization; elaboration of the data collection instrument; data collect; formal analysis; investigation; manuscript writing. Bordin D: methodology design; validation; formal analysis; manuscript writing; final review. Fadel CB: conceptualization; methodology design; 
discussion of the article; manuscript writing; final review. Alves FBT: methodology design; study supervision; writing guidance; project design; final review. All authors have approved the final version of the article.

\section{References}

1. ACOG. American College of Obstetricians and Gynecologists. Committee on Health Care for Underserved Women. Oral health care during pregnancy and through the lifespan, 2013 (reaffirmed 2017).

2. Mark AM. Dental care during pregnancy. J Am Dent Assoc. 2018; 149 (11): 1001

3. Sousa LLA, Cagnani A, Barros MAS, Zanin L, Flório FM Pregnant women's oral health: knowledge, practices and their relationship with periodontal disease. RGO. 2016; 64 (2): 154-63.

4. Catão CDS, Gomes TA, Rodrigues RQF, Soares RSC. Evaluation of the knowledge of pregnant women about the relationship between oral diseases and pregnancy complications. Rev Odontol UNESP. 2015; 44 (1): 59-65.

5. Brasil. Ministério da Saúde. Gestação de alto risco: sistemas estaduais de referência hospitalar às gestantes de alto risco/MS, Sec. Executiva. Brasília, DF; 2001.

6. Paraná. Secretaria de Estado da Saúde do Paraná (SESA) Programa Rede Mãe Paranaense: Linha guia. Paraná SESA; 2018

7. Brasil. Ministério da Saúde. Portaria ${ }^{\circ} 1.459$, de 24 de junho de 2011. Institui, no âmbito do Sistema Único de Saúde (SUS) a Rede Cegonha. Diário Oficial República Federativa do Brasil. 27 jun 2011; Seção 1, p. 109.

8. Moimaz SAS, Rocha NB, Saliba O, Garbin CAS. O acesso de gestantes ao tratamento odontológico. Rev Odontol Univ Cid São Paulo. 2007; 19 (1): 39-45.

9. Brasil. Ministério da Saúde. Caderneta da Gestante. Brasília, DF; 2014

10. IBGE (Instituto Brasileiro de Geografia e Estatística) Pesquisa Nacional de Saúde 2013. Rio de Janeiro; 2013.

11. Bordin D. Qualidade do serviço público odontológico no Brasil: a percepção de usuários e profissionais da saúde [Dissertação]. Araçatuba: Universidade Estadual Paulista Júlio de Mesquita Filho, Faculdade de Odontologia de Araçatuba; 2014.

12. Corchuelo-Ojeda J, Pérez GJG. Determinantes socioeconómicos de laatención odontológica durante lagestaciónen Cali, Colombia. Cad. Saúde Pública. 2014; 30 (10): 2209-2218.

13. Brasil. Ministério da Saúde. Programa de Assistência Integral à Saúde da Mulher. Brasília, DF; 2012.

14. Daalderop LA, Wieland BV, Tomsin K, Reyes L, Kramer BW, Vanterpool SF, Been JV. Periodontal Disease and Pregnancy Outcomes: Overview of Systematic Reviews. JDR Clin Trans Res. 2018; 3 (1): 10-27.

15. Teshome A, Yitayeh A. Relationship between periodontal disease and preterm low birth weight: systematic review.
Pan Afr Med J. 2016; 24 (1): 215.

16. Manrique-Corredor EJ, Orozco-Beltran D, Lopez-Pineda A, Quesada JA, Gil-Guillen VF, Carratala-Munuera C. Maternal periodontitis and preterm birth: Systematic review and meta-analysis. Community Dent Oral Epidemiol. 2019; 47 (3): $243-51$.

17. Offenbacher S, Katz V, Fertik G, Collins J, Boyd D, Maynor G, McKaig R, Beck J. Periodontal infection as a possible risk factor for pré-term low birth weight. J Periodontal. 1996; 67 (10): 1103-13.

18. Chambrone L, Guglielmetti MR, Pannuti CM, Chambrone LA. Evidence grade associating periodontitis to preterm birth and/or low birth weight: I. A systematic review of prospective cohort studies. J Clin Periodontol. 2011; 38 (9): 795-808.

19. Canakci V, Canakci CF, Canakci H, Canakci E, Cicek Y, Ingec M. Periodontal disease as a risk factor for preeclampsia: a case control study. Aust N Z J ObstetGynaecol. 2004; 44 (6): 568-73.

20. Aly LA,El-Menoufy H, Elsharkawy RT, Zaghloul MZ, Sabry D. Maternal chronic oral infection with periodontitis and pericoronitis as a possible risk factor for preeclampsia in Egyptian pregnant women (microbiological and serological study). Future Dental J. 2015; 1 (1): 23-32.

21. Komine-aizawa S, Sohichi A, Hayakawa S. Periodontal diseases and adverse pregnancy outcomes. J Obstet Gynaecol Res. 2019; 45 (1): 5-12.

22. Nogueira LT, Júnior A, Martins CR, Rosell FL, Silva SRC. Retardo na procura do tratamento odontológico e percepção da saúde bucal em mulheres grávidas. Odontol Clin-Cient. 2012; 11 (2): 127-31.

23. RigoL,Dalazen J, Garbin RR. Impact of dental orientation given to mothers during pregnancy on oral health of their children.Einstein. 2016; 14 (2): 219-25.

24. Moimaz SAS, Garbin CAS, Rocha NB, Santos SMG, SalibaNA. Resultados de dez anos do programa de atenção odontológica à gestante. Rev Ciênc Ext. 2011; 7 (1): 42.

25. Merglova, V, Hecova H, Stehlikova J, Chaloupka P. Oral health status of women with high-risk pregnancies. Biomed Pap Med Fac Univ Palacky Olomouc Czech Repub. 2012; 156 (4): 337-41.

26. Codato LAB, Nakama L, Melchior R. Percepções de gestantes sobre atenção odontológica durante a gravidez. Ciênc Saúde Coletiva. 2008; 13 (3): 1075-80.

27. Kateeb E, Momany E. Factors related to high dental caries experience in Palestinian pregnant women in the Jerusalem governorate: a cross-sectional study. Lancet. 2018; 21: 391. 
28. Oliveira LFAS, Rocha RA, França MMC. A Importância do

Pré-Natal Odontológico para Gestantes: Revisão

Bibliográfica. Revista Científica Multidisciplinar Núcleo

do Conhecimento. 2017; 1: 5-17.

Received on May 27, 2020

Final version presented on January 31, 2021

Approved on May 21, 2021 